\title{
How Futurists Look to Uncertainty Phenomena?
}

\author{
Khemis Mohamed
}

\begin{abstract}
This study aims to explore the key assumptions within deferent scenario approaches toward uncertainties which might change the future dramatically, the future is neither uncertain nor linear, and knowing precisely what will happen in the future is almost impossible, futurists do not claim to eliminate this uncertainty through using scenarios, but to reduce it as far as possible. Most of scenario users assume that uncertainties represent opportunities as well as risks, and they are difficult to predict whether the change is sustaining or disruptive, hence they gave much more focus on these phenomena to establish a new mode of thinking to anticipate and prepare to face wild cards of the future. This paper takes different typologies of scenarios as a referring concept to determine methodological tools in terms to build a solid knowledge around what is certain and uncertain, and intended to draw attention to the possibility of critical uncertainties, and also aimed to explain the epistemological vitality of scenario building approaches to understand discontinuities.
\end{abstract}

Index Terms-Complexity, scenario approaches, scenario building, uncertainties, wicked problems.

\section{INTRODUCTION}

Often, managers prefer to make decisions far as possible from the illusion of uncertainty and the lack of knowledge, but there have been studies about the danger of analytical hubris and risks of denial, because uncertainty denial sets the stage for surprises, shattering the managers' confidence in their ability to look ahead.

Uncertainties represent events that cannot be fully anticipated as characterized in futurology literature, such events are very difficult to play effectively -at least two reasons apply-first, by their reversal of significant trends, thereby undermining the facts upon which future planning is built. Second, many of these events fall outside the scope of conventional methods of planning.

Although, Scenario approach work to enable organizations and individuals to better interpretation of changes, uncertainties, and discontinuities, and introduce a new way of thinking based on a new epistemology that provide us to deconstruct the elusive nature of $21^{\text {st }}$ century problems. According to futurist such as Gaston Berger this new approach requires "seeing far, wide and deep; thinking about humankind and taking risks. To do so three characteristics must be involved, often neglected:

1) See differently;

2) See collectively;

3) Use methods as rigorous and participatory as possible to reduce the unavoidable biases in a group.

Mauscript received August 9, 2012; revised November 10, 2012.

Khemis Mohamed is with the University of Kasdi Merbah, OuarglaAlgeria (e-mail: khemiss-moh@ hotmail.com).
The objective of using scenarios is to think differently, and ask different questions by challenging the established modes of thinking.

\section{WiKed PROBLEMS AND UNCERTAINTY}

Scenario as unconventional approach attempts to tame wicked problems when simple solutions fail, because these type of problems require approaches that enable collaboration across multi-disciplinary approach by using multiple types of knowledge, they are likely to require people to change both mindsets and behaviors

Uncertainty phenomena can be defined as "randomness with unknowable probabilities, these might be termed "wild cards" events or "Black Swans"- events that are essentially wholly unanticipated". Andrew Krepinevich has drawn significant parameters of uncertainty phenomena as follows:

1) They are difficult to predict (sustaining or disruptive);

2) A little bit means a lot (small changes can yield big payoffs);

3) There are may be little time to adapt for those who fail to anticipate and prepare to adapt uncertainties;

4) They present opportunities as well as risks;

5) The newly dominant forces characteristics tend to underperform current force characteristics in at least area.

Furthermore, uncertainty needs to be more than lack of knowledge, scientific or any type. If we are to tackle wicked problems we need to pay attention to the co-evolution of knowledge and ignorance.

Dramatic changes are potentially too urgent and too "wicked" to be resolved by conventional methods of scientific inquiry. Instead, we suggest they demand processes of post-normal science methodology. Conventional methods limit its analysis to the current competitive environment in the name of short term profits, meanwhile, many uncertainties hang in the balance within the general context, especially over the long term, underscores the need for scenario approach to clarify strategic options and to ensure continued organizational growth. (See Fig. 1)

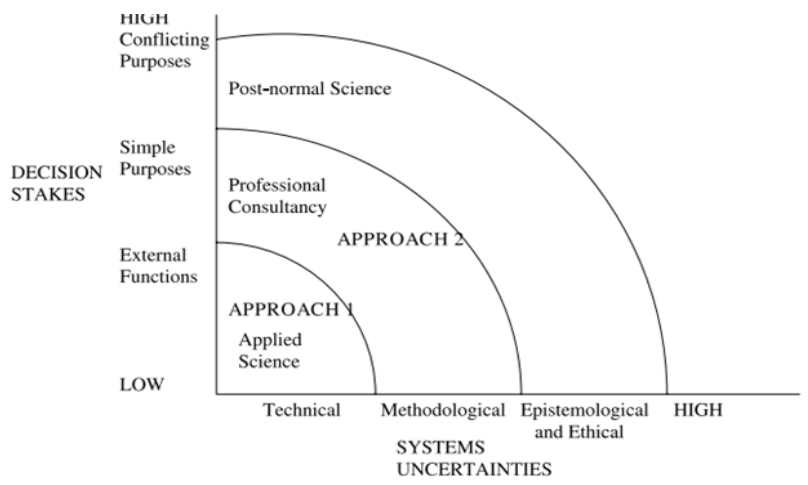

Fig. 1. Existing scenario approaches and their relation to the context of decision stakes/uncertainty. 
For the business managers they have no way but to make decisions, and make them now, and the rest of the stampeding world will not wait until certainty appears, anything can help to make decision in the midst of uncertainty will be valuable, such a tool is scenario approach.

In these contexts, scenarios is revolutionary method (post-modern science) to highlight our future in world of extreme uncertainty, scenarios tell us stories to help us to recognize and adapt to changing aspects of our present wicked problems. "You could use scenarios to plan business, to choose education, to look for job, to judge an investment, or even to contemplate a marriage".

Despite of, the absence of consensus among futurists about scenario definitions, characteristics, principles and methodological ideas, there is a latent epistemological coherence between them about departure point that embodies the central principals of the discipline:

1) It is vitality important that we think deeply and creatively about the future, or else we run the risks of being surprised and unprepared.

2) At the same time, the future is uncertain so we must prepare for multiple futures, not just the one we expect to happen.

3) The ultimate goal of generating scenarios is to understand the mix of strategies and decisions that are of maximum benefits in the face of various uncertainties and challenges emerged from external environment.

4) The process of scenario building contributes the users and planners to develop their anticipatory awareness. Since change continues to accelerate, plans can change. The mind better is able to anticipate is more able to manage change.

5) Scenarios use plausibility as a holistic view to project trends and events and their consequences into the future and generate alternative scenarios at predetermined points in time. Charles Taylor was a futurists, with U.S. Army College of War has developed a "Cone of Plausibility" to encompass theoretical of four planning scenarios; each having a dominant theme or driver, such as technology, economics, politics, and sociology

Most of scenario approaches contains the stories of these multiple futures, from very likely expected to the wild cards, in forms that are analytically coherent and imaginatively engaging. A good scenario grabs us and says "Take a good look at this future. This could be your future. Are you going to be ready?" In general, scenarios describe a future history -that is, the evolution of present conditions to one of several futures.

\section{Military UnCERTAINTIES IN HERMAN KAHN'S APPROACH}

The scenario method is more than new way of thinking, but a way of grappling with high levels of both complexity and uncertainty and then making decisions. Herman Kahn was the earliest futurists during 1950s and 1960s, which used scenario planning as methodological tool to deal with uncertainty and complexity that are deliberately built into war situations.

In US Department of Defense the uncertainty was so high about what projects should be funded for the development of new weapons systems, a difficult undertaking giving increasing complexity of weapons systems arising from advances of emerging driver forces of science and technology in post-World War Two era. According to Herman Kahn the difficulty of assignment was the significant uncertainty faced on three fronts by the decision makers.

Firstly: The end result of the development of new weapons systems which generally required long lead times was itself uncertain.

Secondly: With lowering of the "iron curtain" there was a high degree of uncertainty as the future political environment under which the systems being developed would be deployed.

Finally: Uncertainty as to the effectiveness of systems ultimately developed as this would be largely dependent upon what weapons systems other nations developing

The decision making in these contexts gave a rise of two specific needs, the need for methodology to capture the reliable consensus of opinion of a large and diverse group of experts; and the need to develop simulation models of future environments which would permit various policy alternatives and their consequences to be investigated

Kahn began in 1950s developing scenarios for the Air Defense Missile command, a large scale early warning system. He variously described as a "super genius" and a "policy intellectual of unquestioned genius" developed a disturbing critique of US military strategy in the thermonuclear age.

Kahn demonstrated through a combination of facts and logic, that military planning tended to be based on wishful rather than "reasonable expectations" the existing doctrine he contended was disastrous, and he demonstrated this by developing scenarios of a "nuclear war was miscalculation".

Using scenarios for Kahn was a vehicle to "think about unthinkable", and to search for plausible alternatives to annihilation and surrender, and his work had a major impact on the pentagon's thinking in 1950s and 1960s.

Additionally, he argued that the purpose of scenario is to systematically explore, create, and test both possible and desirable futures; scenarios with this meaning can help generate long-term policies, strategies, and plans that can help to bring desired and likely future circumstances in closer alignment.

When any one or organization confronts complexity and uncertainty, two risks become apparent: the risk of paralysis and the risk of denial which freeze us into inactivity. For that reason, the ultimate aim in Kahn approach is to create a shared language for thinking, talking about and shaping the future. This new vocabulary is essential to making collective actions possible by using scenarios in strategic conversation, and allowing individuals or groups to (re)align their understanding of the possible future.

\section{PIERRE WACK APPROACH TO ECONOMIC UNCERTAINTIES}

Every organization has its own uncertainties to cope with, in doing so, Pierre Wack and Ted Newland among other planners in Dutch-Shell Company tried to imagine significant 
discontinuities would disrupt their company position if oil prices system will change in the next 10 or 20 years.

Shell was frustrated by the fact that they had no chance but make large capital investments in face of extreme uncertainty came from a large multiple variables e.g., whether they should invest on off-shore platforms or explore in new fields.

So Pierre Wack and his teammates built up two scenarios: The first presented the usual opinion at Shell about the future: that the oil prices would stay somehow stable, but in order for that to happen, a miracle would have to occur. The second scenario supposed another future based on oil price crisis sparked by Organization of Petroleum exporting Countries (OPEC) .

Pierre Wack and Ted Newland realized that scenario approach was the appropriate tool to deal with rising complexity in short time and limited resources, the United States was beginning to exhaust its oil reserves, the demand for oil was steadily rising, and the emerging OPEC was showing signs of flexing its political muscles. Most of these countries were Islamic, and they bitterly resented western support of Israel after 1967 Arab Israeli Six-Day War. In fact, this multi-factorial problem was extremely wicked to resolve by conventional tools.

This new analytical approach inspired Shell's mangers to imagine the decisions they must to take as a result. And it was just in time. In October 1973 after Yom Kippur War in the Middle East, There was an oil price shock, and Shell was already well prepared for the change.

\section{FUTURE FRENCH SCHOOL'S APPROACH TO UNCERTAINTY}

The futures French school of la prospective developed broad thinking skills to deal with uncertainties, according to Michel Godet who argued that: "Whatever uncertainties loom on the horizon, every organization is confronted with the same trends and must deal with the same ruptures in the future." We cannot ignore the cross impact matrix of uncertainties and trends and how anticipate it, scenario building in Godet's approach is all about anticipation which clarifies actions and gives it a meaning and directions.

For sake of clarity, anticipation should be imperative in the contemporary business climate that contains following dynamics:

1) Social, economic and technological change is accelerating, hence the need for long term vision;

2) The factors of inertia inherent to various structures and behaviors oblige us to sow now if we want to reap the future harvest later.

The world may well be changing but the direction of that change is not certain. Shifts and transfers trigger social, economic, and technological uncertainty that people and organizations have to integrate into their strategies for the future. Hence, Godet emphasizes on scenario building and future-thinking to reduce uncertainty as much as possible. And scenario building needs to be appropriate enough to turn anticipation into action. (See Fig. 2)

Despite the imperfection of tools, the inaccuracy of data, and the subjectivity of interpretations are inevitable, the futurist has to opt for trans-disciplinary and complementary



Fig. 2. Prospective gives content and direction to collective mobilization.

For that reason, Michel Godet has been developed a tool box which classifies problem-solving methods as follows:

1) Asking the right questions and identifying the key variables: future workshops and structural analysis with MICMAC method;

2) Analyzing trends and actors strategies: retrospective studies and MACTOR method;

3) Reducing uncertainties to likely scenarios: morphological analysis, expert methods (Delphi, cross-impact analysis);

4) Identifying and assessing the strategic options: multi-criteria analysis and MULTIPOL method.

According to Godet, La prospective does not pretend to make an uncertain future certain, but he argues that: it does help to provide organizations and individuals to make various possible futures. He suggested that future becomes ever more uncertain and complex, and the pace of change accelerates, organizations need to change, but by anticipating it. "The faster you drive, headlights must shine."

Additionally, as structures and patterns of behavior become more complex, the inertia to be overcome in order to change both of them increases. "Fatalism" says Godet, passively letting the future happen, is no longer an option.

\section{MorphologicAl ANALysis to ReducE UNCERTAINTIES}

Yet, certain futurists wanted to develop rigorous methods to reduce uncertainties in the future (including Godet), because they think that proverbial "BOGSAT" (Bunch of Guys Sitting around Table) methods are too old and not useful in building scenarios. Moreover, a more rigorous method they have found for scenario building is the morphological analysis.

Scenarios are designed to recognize the capability for different operational situations. But, rising complexity presents us with a number of methodological problems. Especially, the uncertainties inherent in scenario modeling are principle non-reducible and involve conscious self-reference among actors.

In the early of 1940s professor as Fritz Zwicky at the California Institute of Technology in Pasadena began to develop a methodological basis able to describe how relevant parameters are identified, and how these parameters related to each another. He called it Morphological analysis. 
Morphological analysis is non-quantified modeling method for structuring and analyzing technological, organizational and social wicked problems and complexities. Morphological analysis contains two phases:

Analysis phase: it begins by identifying and investigating the total of set possible relationships or "configurations" contained in given problem complex and;

Synthesis phase: from these parameters, consistent configurations (alternatives) are derived by considering the consistency between conditions for different parameters in a pair-wise fashion

In morphological analysis, a morphological field is prepared by setting the parameters against each other in order to create an n-dimensional configuration space. (See Fig. 3)

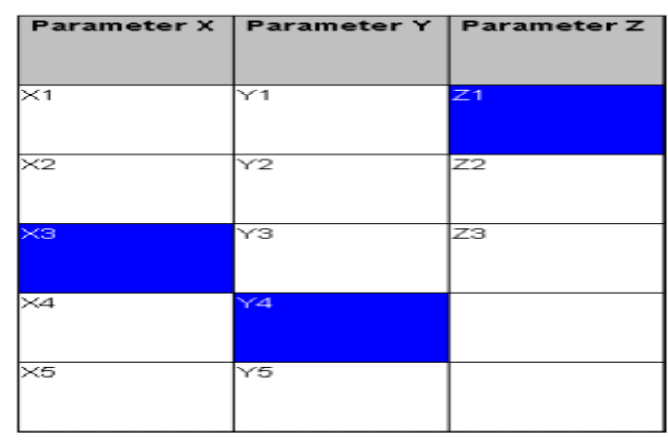

Fig. 3. Morphological analysis.

Each of the parameters is shown in column, with the possible condition as boxes in the column (e. g, four fold tables)

In the analysis phase we must to examine internal relationships between the parameters and reduce the field by weeding out configurations which contains mutually contradictory conditions. Then we create a preliminary outcome or solution space within the morphological field without having first to consider all of the configurations as such.

The most important aspect in morphological analysis is the comparison of all parameters values with one another, pair-wise, in the manner of cross impact matrix.

\section{CONCLUSION}

All above of discussion focuses on the main points of uncertainty and complexity between different approaches of scenario building and futurists. Two final observations in this respect are that:

Firstly, scenario building approaches represent a new paradigm to deal with uncertainty and wicked problems especially, when simple solutions (normal science) fail. However, scenario building approaches need to involve a multidisciplinary approach and further more they must create a shared strategic thinking, talking about and shaping the future.

Secondly, while the differences between scenario approaches about the definitions, characteristics, principals and methodological coherence are readily apparent, the departure point still embodies the central principals of the discipline $\mathrm{e}, \mathrm{i}$.

It is vitality important that we think deeply and creatively about the future, or else we run the risks of being surprised and unprepared. At the same time, the future is uncertain so we must prepare for multiple futures, not just the one we expect to happen.

\section{REFRENCES}

[1] A. Wilkinson and E. Eidinow, "Evolving practices in environmenta scenarios: a new typology," Environmental Research Letters, no. 3 , pp.1-11, 2008.

[2] C. Ertel and M. Walton, Connecting Present with Future, pp. 1-8, 2006.

[3] D. Meitzner and G. Reger, "Advantages and disadvantages of scenario approaches for strategic foresight," Technology Intelligence and Planning, vol.1, no. 2, pp. 220-240, 2005.

[4] M. Godet and F. Roubelat, "Creatinf the future: The use and misuse of scenarios," Long Range Planning, vol. 29, no. 2, pp. 164-171, 1996

[5] M. Godet, Creating Futures: Scenario Planning as Strategic Tool, $2^{\text {nd }}$ ed. France: Economica, pp. 2, 2006.

[6] M. Godet, Strategic Foresight: La prospective Use and Misuse of Scenario Building, Paris: CNAM, pp. 26, 2007.

[7] P. Shwartz, The Art of Long View: Planning for the Future in Uncertain World, New York: Doubleday, pp. 5, 1991.

[8] P. Bishop, A. Hines, and T. Collins, "The current state of scenario development: an overview of techniques," Foresight, vol. 9, no. 1, pp 5-25, 2007.

[9] R. Bradfield, G. Wright, G. Burt, G. Cairns, and K. V. D. Heijden, "The origins and evolution of scenario techniques in long range business planning," Futures, no. 37, pp. 795-812, 2005.

[10] T. Erickson and T. Ritchy, "Scenario development using computerized analysis," in proc. Winchester International OR Conference, England pp. 1-9, 2002

[11] T. Ritchy. (February 2012). Developing scenario laboratories with computer-aided morphological analysis. in proc. $14^{\text {th }}$ International Command and Control Research and Technology Symposium, pp. 1-13. [Online]. Available: http://www. swemorph.com/pdf/cornwalls3.pdf

[12] L. Wilkinson, "How to build scenarios: planning for long fuse big bang," Special edition, pp. 1-4, 1995.

[13] C. W. Taylor, "Eliminate future shocks," Defense Investment Strategies in Uncertain World, pp. 12-15.

[14] D. C. Washington, Center for Strategic and Budgetary Assessments, pp. 6-10, August 2008.



Khemis Mohamed was born in Ouargla- Algeria $14^{\text {th }}$ june 1980 . He is a $\mathrm{PhD}$ candidate in Future Studies at the University of Algiers 03. In the Field of studies: strategic and future studies. He is assistant professor in future studies. at University of Kasdi Merbah, Ouargla-Algeria. Member of research project in Euro-Mediterranean relations issues ( $\mathrm{Al}$ alakat el-euro motawasitia). And a member in laboratory of political, social, economic and strategic transformations in Algeria, code: S02420110024 (Al-tahoulat al-siyassiawa al-ijtimaaiawa al-iktisadiawail-istrategia fi al-djzaier). Last article released (In Arabic) titled "The impacts of oil upturns on development programs of OPEC countries" Dafatir al-siyassawa al-kanoun, no. 6,pp. 298-305, January 2012 